\title{
Enseñanza-aprendizaje y tecnologías de comunicación y conexión (TCC): el eje virtualización-actualización
}

\author{
Cesáreo FERnÁndez FERnÁndeZ \\ Universitat Jaume I (Castellón) \\ cfernand@uji.es
}

Recibido: $27 / 07 / 2012$

Aceptado: 29/10/2012

\section{Resumen}

Al considerar la web en el ámbito de la enseñanza-aprendizaje, interesa más entenderla como una TCC (Tecnología de Comunicación y Conexión) que como una TIC. Muchas veces, la tecnología actual sólo se emplea desde sus posibilidades meramente conectivas (entre otras, de suministro y búsqueda de información), sin concebirla desde todas las potencialidades que posee de virtualización. En este texto se plantea el rol de la tecnología -y su imbricación funcional- en la formación, desde la necesidad de atender a lo virtual cuando nos enfrentamos al conocimiento y su transitivización.

Palabras clave: tecnologías de red, e-learning, blended learning, lo virtual, educación-aprendizaje

\section{Teaching-learning and communication \& connetion technologies (CCT): the virtualization-actualization axis}

\begin{abstract}
When considering the web in the field of teaching-learning, it's better to consider it as CCT (Communication and Connection Technology) than as a CIT. Many times, current technology is used only from merely connectives possibilities (e.g. supply and information retrieval), without conceiving it from all the potentialities that has of virtualization. In this paper we discuss the role of technology -and its functionality- on teaching-learning, from the need to attend to the virtual when we face knowledge and its transitivity.
\end{abstract}

Keywords: network technologies, e-learning, blended learning, virtual, teaching-learning

\section{Referencia normalizada}

FERNÁNDEZ FERNÁNDEZ, Cesáreo (2012): "Enseñanza-aprendizaje y tecnologías de comunicación y conexión (TCC): el eje virtualización-actualización”. Estudios sobre el mensaje periodístico. Vol. 18, núm. especial octubre, págs.: 303-311. Madrid, Servicio de Publicaciones de la Universidad Complutense.

Sumario: 1. Introducción. 2. Metodología. 3. Desarrollo; 3.1. Virtualización y web; 3.2. Pensar desde lo virtual la tecnología para la enseñanza-aprendizaje. 4. Conclusiones. 5. Referencias bibliográficas.

\section{Introducción}

Más allá de sus enormes posibilidades conectivas (entre otras, para el suministro y búsqueda de información), la web tiene su mayor virtud, precisamente, en sus potencialidades de virtualización. La formación (la enseñanza-aprendizaje) -al igual que ocurre con la producción industrial, profesional, cultural, etc.- cada vez se desarrolla más apoyándose, o concibiéndose íntegramente, sobre procesos on-line o, digamos, en web -entendida la web (red) como aquella tecnología que subtiende la comunicación, o conexión, tele-crono-rete-electro-info-digital. Al decir esto así, se pretende reclamar la atención sobre la diferencia que, tanto en los procesos de producción como en los de formación, existe entre los mecanismos comunicativos frente a los conectivos, 
a la vez que reclamar la atención sobre la condición que, sin embargo, ambos ostentan hoy, en cuanto que conjugadores de los seis parámetros que unen los guiones, esto es, el de la distancia (tele), la temporalidad (crono), la reticularidad (rete), la electrónica (electro), la informática (info) y la digitalización (digital).

La formación basada en tecnologías web -y en particular en los sistemas denominados EVE/A (entornos virtuales de educación-aprendizaje)- descuida en demasiados casos o, precisamente, desvirtúa, lo virtual. Ciertamente, en algunas metodologías formativas y para algunas facetas de áreas técnico-científicas, plataformas tecnológicas como Moodle pueden facilitar la evaluación continua del estudiantado (sobre todo mediante test), en la línea que postula el así denominado como EEES (Cuesta y Alegre, 2012: web). Pero no es así, al menos de manera generalizada, en el caso de las ciencias humanas y sociales, y, además, el mayor aporte que pueden suministrar las tecnologías web a la formación, no es en los procesos de evaluación (estimar, apreciar, calcular el valor de algo), sino en los de validación (dar fuerza o firmeza a algo, hacerlo válido). Como señalan Bernad y Solá (2007: web) "es necesario proponer un nuevo método para complementar la docencia en la que el alumnado sería parte activa e implicada en la elaboración de la misma". Y es que, junto a las ventajas de las tecnologías digitales, también hay que considerar sus problemáticas. Como dice Zeynep Arda (2011: web), "corta, informal, sin compromisos, sin complicaciones, la comunicación digital está a golpe de clic. [...] La forma en que socializamos comienza a inclinarse más hacia una relación de voyeurismo/exhibicionismo". Y esto puede suponer, de hecho supone, un cierto riesgo para la optimización y plenitud de los procesos comunicativos - especialmente al pensarlos al servicio de la formación. El riesgo mayor es pues pensar en la web como herramienta de potenciación conectiva en vez de pensar en sus potencialidades comunicativas, las cuales residen en las capacidades y riqueza de sus modos de virtualización. En este sentido, hay que pensar las nuevas tecnologías sin abandonar las referencias humanas: "la cultura de la web 2.0 no es sino un nuevo modismo para tildar lo que antes definíamos como "hacer algo en grupo'. [...] El grupo de usuarios alimenta el medio y el mensaje y lo hace crecer" (Caldevilla, 2010: web).

Respecto de la web, muchas veces se piensa más en posibilidades que en potencialidades. Algo que también ocurre hoy en día respecto de otro medios. Así, las actuales tendencias de producción low-tech/low-cost en televisión, desarticulan las potencialidades de virtualización de ese medio que pudieran favorecer la difusión de la cultura, y, desde estrategias basadas en técnicas de "directo-sucedáneo" "generan modelos preformateados en que se busca "hacer conocimiento de la metonimia arbitraria" (Fernández, 2012: web), en vez de promoverlo en la metáfora. Restringir la metáfora es restringir el valor de la interpretación y el poder creativo del receptor- lo cual también ocurre en al ámbito hipermedia cuando no se piensa desde la virtualización. Lo que Galán (2012: web) propone respecto del medio televisivo, al afirmar que "la transparencia en los procesos productivos debe ser un imperativo que determine su nivel cualitativo y ético", es algo igualmente aplicable en el ámbito de la formación asistida o basada en web. Esa transparencia de la tecnología de producción (en el caso que nos ocupa, respecto de los procesos de enseñanza-aprendizaje) es la que asegura 
que no se pierdan las potencialidades comunicativas de la web en favor de las simplemente conectivas, por muy deslumbrantes que sean estas últimas.

\section{Metodología}

Parece, desde luego, mucho más fructífero pensar los procesos de producción y enseñanza-aprendizaje actuales, respecto de la diferencia entre los procesos de comunicación y los de conexión -y de la exaparametrización que hoy subtiende a ambos- que no hacerlo en términos de si se dan en el seno de la web 1.0, 2.0 o 3.0 (¿y porqué no la web 3.14?). Se intentará salvar la desproporción que, para la extensión de este texto, supone pensar la optimización de las potencialidades de la tecnología (web) en los procesos de enseñanza-aprendizaje, siguiendo una estrategia metodológica doble. Por un lado, avanzar desde un planteamiento de la tecnología web basado en conceptos selectivos que se consideran esenciales (y, por tanto, diríamos clásicos, necesariamente de libro) hacia una concepción de la formación on-line (valga la etiqueta) basada más en ideas y estudios recientes (sobre todo de artículos). Y, por otro lado, cómo dice Andreu Carandell (en Hoghe, 1989: 10) en el prólogo a un libro sobre Pina Baush, mediante la estrategia metodológica de "no dar las cosas muy masticadas, no acabar de explicar [...] acercarse, esbozar, sugerir [...] eso, antes de ser una dificultad es una ayuda. El lector se sentirá exigido, reclamado a completar".

\section{Desarrollo}

\subsection{Virtualización y web}

El considerado como creador de la www, Tim Berners-Lee criticaba el término de web 2.0, calificándolo de jerga, que Tim O'Reilly y otros acuñaran en torno a 2004 para referir a las evoluciones de la web que la convertían en algo más cercano a la colaboración entre usuarios que a ser algo para la mera observación. Igualmente, cuando en 2006 Jeffrey Zeldman acuñaba el término de web 3.0 para referir a la evolución de la web hacia lo que podríamos resumir como la gestión semántica y participativa de bases de datos colaborativas, no estaba sino añadiendo otra etiqueta a una jerga poco significante, sobre todo para el conjunto de la sociedad. Porque, si bien es verdad que la tecnología, plataformas y programas, de implementación de la web han evolucionado, no lo han hecho por saltos ni han creado en sí algo que no estuviera ya en potencia desde los orígenes de la web y, diríamos más, desde los orígenes de la propia condición y sociedad humanas, en que la noción de red -en tanto que estructuración de las formas de interacción entre individuos y grupos- ha ido produciendo lo que Pierre Lévy denomina el proceso de hominización (para no ser sexista podríamos decir proceso de humanización). Algo que se puede encontrar en muchos otros autores y conceptos pero que Lévy desarrolla en textos de grandísimo interés, ya desde la década de los 80 del S.XX, con títulos y conceptos tan sugerentes al respecto de lo que venimos diciendo como: La Máquina universo. Creación, congnición y cultura informática (1987); Las tecnologías de la inteligencia. El futuro del pensamiento en la era informática (1990); La ideografía dinámica ¿Hacia una imaginación artificial? (1991); La Inteligencia colectiva. Para una antropología del ciberespacio (1994); ¿Qué es lo virtual? (1995), entre otros. Igualmente, muchos años antes de que se hablara de web2.0, Dominique Monet afirmaba: 
"Desde el final del siglo XIX, y dado que la comunicación social se organiza en torno al 'mensaje' y a su circulación, era impensable que su evolución continuase hacia lo totalmente digital sin explotar la riqueza de los sonidos, de las ilustraciones musicales, gráficas, fotográficas, y de las secuencias animadas de tipo vídeo, es decir, de evolucionar hacia la forma multimedia”. (Monet, 1995: 19)

Aquí, es interesante fijarse además en esa doble condición de lo nuclear de la comunicación social: el mensaje (comunicación en sí) y su circulación (conectividad). Y es que, merece la pena destacar que, la condición reticular de la comunicación humana, es algo que no nace con la web. La particular estructura conectiva que define la noción de red y que condiciona las formas de comunicación, su evolución y potencia (tanto de mensaje como de comunidad) es algo que emerge y se desarrolla desde tiempos remotos. Baste pensar en las formas primitivas de red comunicacional (en relación a la circulación de información) que representaba el correo (mucho antes del conocimiento de la electricidad), el telégrafo, etc. Por otro lado, al referir a la "forma multimedia", no sólo cabe entender la noción de "media" aplicada a, digamos, canales sensoriales, $\mathrm{u}$ objetos sensibles, sino también a la misma condición de fuente intelectual que cada individuo representa (tanto de forma aislada como en cuanto a célula de una comunidad). La propia Dominique Monet (1995: 112), ya decía en 1995 que "el hipertexto, los hipermedia y la consulta de bases de conocimiento almacenadas o accesibles en red [...] permiten trabajar en tiempo real en proyectos comunes en grupos temáticos ad hoc en las redes". Por lo tanto, pensar las potencialidades de la web desde los desarrollo tecnológicos concretos que implementan su funcionalidad en cada momento es algo reduccionista, por cuanto que, tal forma de proceder, limita las capacidades expansivas y optimizadoras de lo que en verdad más importa respecto de la web en sí, esto es el conocimiento humano, así como la capacidad de imaginación, creatividad e innovación orientadas a su desarrollo y al servicio social. Esto es lo primero, y lo que debe propiciar, a su vez, el desarrollo de las tecnologías. Pensarlo en orden inverso sólo lleva a "crear una sociedad fundamentada sobre la apariencia, una sociedad que excluiría todo rigor intelectual y todo espíritu de análisis, y que aboliría las nociones de paciencia y de concentración, ya sea en materia de ocio, información o enseñanza". (Monet, 1995:106).

Someterse o restringirse a la consideración de las tecnologías web como gestoras de lo posible y no de lo virtual es, precisamente, anteponer en orden operativo y esencial la tecnología al intelecto, lo cual, por desgracia, ocurre demasiadas veces a la hora de pensar la enseñanza-aprendizaje en/con web. Dice Pierre Lévy (1995: 135) que "posible y virtual tienen un rasgo común que explica su confusión tan frecuente: los dos son latentes, no manifiestos [...] mientras que real y actual son ambos patentes o manifiestos".

\begin{tabular}{|l|l|l|}
\hline & Latente & Manifiesto \\
\hline Sustancia & Posible (insiste) & Real (subsiste) \\
\hline Acontecimiento & Virtual (existe) & Actual (ocurre) \\
\hline
\end{tabular}

"Les quatre pasajes" (los cuatro modos de paso)- Pierre Lévy (1995: 136) 
Para comprender la reivindicación que aquí se hace de la puesta en juego de lo virtual -en detrimento de lo posible- a la hora de considerar y concebir las tecnologías web, vale la pena considerar las siguientes palabra de Lévy:

"De esencia problemática, lo virtual es como una situación subjetiva, una configuración dinámica de tendencias, de fuerzas, de finalidades y de limitaciones que resuelve una actualización. La actualización es un acontecimiento, en el sentido fuerte del término. Se lleva a cabo un acto que no estaba predefinido y que modifica a su vez la configuración dinámica en la cual toma significado. La articulación de lo virtual y de lo actual anima la dialéctica misma del acontecimiento, del proceso, del ser como creación. Al contrario, la realización selecciona entre varios posibles predeterminados" (Lévy, 1995: 135)

Así, la arquitectura tecnológica para la participación que representa la web, es algo que concierne a lo posible-real, mientras que la actividad humana que se desarrolla en la web o gracias a la web, ha de ser concebida y ejecutada como algo que concierne a lo virtual-actual. Debemos seleccionar, comprender, digerir y transformar la masa de informaciones que no enseñan nada por sí mismas, que no son sino datos en bruto que analizar (Monet, 1995: 106).

\subsection{Pensar desde lo virtual la tecnología para la enseñanza-aprendizaje}

Si se opera en/con la tecnología desde el eje posible-real en vez de hacerlo desde el eje virtual-actual, se dejará de ser sujeto de los procesos formativos (el sujeto será la tecnología en sí, operando fórmulas preconfiguradoras, limitadoras de la capacidad de iniciativa, de autonomía, de progreso, en tales procesos), en cuyo caso la tecnología aplicada a la formación puede incluso mermar la idoneidad, calidad o efecto de la misma. ¿Qué tiene de virtual un aula virtual? Como venimos afirmando, su condición de virtual dependerá mucho de cómo opere con ella tanto quien eduque como quien aprenda. Lo que se hace con/en las llamadas aulas virtuales, se podría hacer igualmente (incluso mejor) mediante wikis, blogs, foros, web-sites, chats (de texto, audio y/o vídeo), e-mail, etc. (todo ello dedicado y no dedicado, fuera del "aula virtual"). Los sistemas EVE/A, muchas veces crean, respecto de la materia o asignatura de que se trate, una especie de monocanal para la enseñanza-aprendizaje en/con web, limitan potencialidades por su configuración particular, a la vez que, y esto es lo más pernicioso de tales sistemas, invitan a no aprender, conocer, adaptar, racionalizar, la tecnología en sí al servicio de tales procesos, al producir una cierta colonización operativa de los modos tecnológicos de implementación de la formación, que puede restringir, saturar y hasta bloquear las inercias creativas e innovadoras al respecto.

Haciendo una concesión al etiquetaje generalizante, se puede considerar el e-learning (el e-teaching/learning) como toda forma de educación-aprendizaje que contempla de manera sustancial el empleo de la tecnología (web y cualquier otra plataforma tele-crono-rete-electro-info-digital) y que lo hará en diversa medida, con diversa estrategia, estructura y objetivos. Al respecto, es interesante atender a las inteligentes observaciones de Beatriz Tancredi (2011: web) cuando dice que "la educación a distancia no se opone radicalmente a la educación presencial". Y no sólo por el 
hecho de que ambas puedan compartir en parte la condición de la otra, sino, sobre todo, porque en ambos casos (y asumido, ya hoy, que la concurrencia de la tecnología es inevitable), lo importante será la metodología, los materiales, las dinámicas, estrategias, filosofías, etc. que rijan y estén al servicio de la materia y el proceso de educación-aprendizaje de que se trate. Al final, las ideas de presencialidad, semipresencialidad (blended learning), a distancia, etc., acaban por no significar nada o designar simplemente momentos o modos de "estar". Tancredi (2011: web) afirma, que "se debe sustituir la expresión 'educación a distancia' por la de «educación sin distancia»". Pensar las tecnologías comunicativas y conectivas desde el eje virtualizaciónactualización, es algo que permite crear el eje educación-aprendizaje. Si se piensan desde el eje de lo posible-real, la enseñanza se desliga del aprendizaje. Y eso, con independencia de la modalidad educativa de que se trate o que se siga. Tancredi (2011: web) también aboga, muy acertadamente, por que se haga "la integración de las TIC en la gestión de los sistemas de educación a distancia, desde una perspectiva contextualizada y crítica que parte de asumirlas al servicio de un proyecto educativo, más no lo contrario".

Ocurre que muchas veces se diseña y establecen los programas, los materiales y las metodologías para el aula virtual en sí (o las tecnologías de presentación), y no para la materia, el conocimiento y el estudiantado como tales. En esos casos, como dice la propia Tancredi (2011: web), "se termina por confundir la modalidad educativa con los medios provistos por las TIC". Y, en consonancia con esto, afirman Gabriel Valerio y Jaime R. Valenzuela (2011: web), citando a Burbules y Callister (2000), que "adquirir las habilidades para tener acceso es sólo parte del problema, ya que el mayor reto está en desarrollar las disposiciones y actitudes para obtener un uso efectivo de las tecnologías". En esta cita se habla, acertadamente, de "disposiciones y actitudes" en vez de "competencias y aptitudes". Lógicamente, desarrollar y posibilitar estas últimas también es algo necesario, pero parece que se suele insistir más sobre ellas (como hacen los impulsores del pretendido EEES) que sobre las primeras. En relación a esto, es muy interesante la referencia que hacen José Zagal y Amy Bruckman al mecanismo de "Legitimate Peripheral Participation (LPP)" -que traducido vendría a ser Participación Periférica Legitimada (PPL)- desarrollado por Lave y Wenger (1991), y descrito como "una parte crucial del aprendizaje en una comunidad de práctica. Inicialmente, un miembro participará en actividades que sean importantes (legitimado) para la comunidad, pero no sean tal vez el foco central de las prácticas de tal comunidad [...]. Un periodo extenso de periferialidad legitimada ofrece al novato oportunidades de desarrollar la cultura de la práctica por sí mismo. Esta noción destaca la diferencia entre 'tomar parte' y 'ser parte' " (Zagal y Bruckman, 2010: web). Es decir, las capacidades de adaptación y de iniciativa autónomas del estudiantado, deben ser consideradas en toda metodología que se valga de calidad, y, en particular, respecto de las tecnologías (entendidas, en relación a la cita anterior, como esas actividades "que sean importantes [...] pero no sean el foco central").

Volviendo a Tancredi, nos dice, en relación al e-learning, que "tampoco se redefiniría esta modalidad educativa por el uso exclusivo de las TIC por sobre la exclusión de un amplio menú de tecnologías clásicas, conocidas por el término 'legacy techno- 
logies' que continúan demostrando su pertinencia bajo determinadas situaciones contextuales" (Tancredi, 2011: web). Y es que, paradójicamente, la llamada formación on-line, en muchos casos, apoya y fundamenta los diversos módulos o asignaturas que componen los cursos y programas (carreras, masters y cursos de especialización, fundamentalmente) sobre textos, monografías y compendios escritos, producidos ad hoc para la materia, el estudiantado y la metodología concreta de que se trate. Lo cual ha supuesto algo que es, en cierta manera, lo opuesto a cierta tendencia esquizofrénica de las formas de escritura y lectura en la red y en las plataformas y dispositivos tecnológicos. Esto es, la lectura reposada, analítica, centrada, de textos continuos y estructurados, que remite a los conceptos de paciencia y concentración que refería Dominique Monet en una de las citas precedentes.

\section{Conclusiones}

Son los procesos de enseñanza-aprendizaje los que deben condicionar, modular o determinar, en cada caso, las tecnologías que incorporen o implementen, y no al revés, para que, en su combinación, sea el eje de lo virtual-actual lo que se ponga e juego y no el de lo posible-real. La conectividad, la accesibilidad, la interactividad, no son por si mismas un valor si no sirven a procesos de esencia comunicativa. De ahí que pudiéramos decir que pensar la tecnología al servicio de la educación-aprendizaje supone pensar en la comunicacción (con dos c's intermedias que remiten a las propias tecnologías pero con el grueso de la palabra remitiendo a esa esencia humana -intelectual y emotiva- de los procesos).

El establecimiento del llamado EEES ha supuesto reforzar la atención sobre aspectos del tipo competencias, aptitudes y habilidades. Pero se ha visto que tan importantes como esos aspectos, son los de disposición y actitud, también frente a las tecnologías en sí (y además, tanto por parte de quien aprende como de quien enseña).

Tal vez, la conclusión final, por todo lo dicho, y a modo de corroboración de una hipótesis -basada en la conjugación analítica de los argumentos propios y ajenos expuestos- podría formularse sintéticamente como que, la manera óptima de enseñaraprender en relación a la era tecnológica que vivimos, sería pensar en procesos de web\&legacy-teaching-learning (WLTL) - donde, en una pirueta denotativa, se incluye la idea web como metáfora general de las tecnologías comunicativas y conectivas telecrono-rete-electro-info-digitales, y, se incluye la idea de herencia, legado, como metáfora de las formas tradicionales de comunicación y conexión humanas.

\section{Referencias bibliográficas}

ARDA, Zeynep (2011): Image Becomes Identity 2.0: Contemporary Approaches to the Construction of Human Identity. Tesis doctoral (ISBN: 978-84-695-4268-2): http://hdl.handle.net/10803/81855

BERNAD MONFERRER, Estela y SOLÁ CLIMENT, Rosario (2007): "Alfabetización mediática: una estrategia para el acercamiento de la educación", en FISECEstrategias, III, nº, pp. 65-88: http://www.fisec-estrategias.com.ar/ 
BURBULES, Nicholas y CALLISTER, Thomas (2000): Watch it: the risks and promises of information technologies for education. Boulder, Colorado (EE.UU), Westview Press

CALDEVILLA DOMÍNGUEZ, David (2010): "Las redes sociales. Tipología, uso y consumo de las redes 2.0 en la sociedad digital actual", en Documentación de las Ciencias de la Información, vol. 33, pp. 45-68: http://revistas.ucm.es/index.php /DCIN/article/view/DCIN1010110045A

CUESTA SEGURA, Isidoro y ALEGRE CALDERÓN, Jesús (2012): “Uso de la plataforma Moodle como herramienta para la evaluación continua de estudiantes en el Espacio europeo de Educación Superior", en Revista de Comunicación Vivat Academia, XIV, $\mathrm{n}^{\circ}$ especial, pp. 417-428: http://www.ucm.es/info/vivataca/numeros/n117E/PDFs/Varios8.pdf

FERNÁNDEZ FERNÁNDEZ, Cesáreo (2012): “El 'directo sucedáneo' como formato de producción low cost/low human resources en el periodismo TV", en Revista de Comunicación Vivat Academia, XIV, $\mathrm{n}^{\circ}$ especial, pp. 1239-1251: http://www.ucm.es/info/vivataca/numeros/n117E/PDFs/CFerna.pdf

GALÁN CUBILLO, Esteban (2012): "Estrategias para abordar la información audiovisual sobre el patrimonio inmaterial de los territorios desde una perspectiva interactiva: el papel de las redes sociales", en Revista de Comunicación Vivat Academia, XIV, $\mathrm{n}^{\circ}$ especial, pp. 1089-1099: http://www.ucm.es/info/vivataca/numeros/n117E/PDFs/EGalan.pdf

HOGHE, Raimund (1989): Pina Baush, historias de teatro-danza. Barcelona, Ultramar.

LAVE, Jean y WENGER, Etienne (1991): Situated Learning: Legitimate Peripheral Participation. Cambridge (UK), Cambridge University Press.

LÉVY, Pierre (1987): La Machine univers. Création, cognition et culture informatique. Paris, La Découverte.

LÉVY, Pierre (1990): Les Technologies de l'intelligence. L'avenir de la pensée à l'ère informatique. Paris, La Découverte.

LÉVY, Pierre (1991): L'Idéographie dynamique. Vers une imagination artificielle? Paris, La Découverte.

LÉVY, Pierre (1994): L'Intelligence collective. Pour une anthropologie du cyberspace. Paris, La Découverte.

LÉVY, Pierre (1995): Qu'est-ce que le virtuel? Paris, La Découverte.

MONET, Dominique (1995): Le Multimédia. France, Flammarion.

TANCREDI GUERRA, Beatriz (2011): “Apuntes para resignificar la educación a distancia”, en RIED: Revista Iberoamericana de Educación a Distancia, Vol.14, ${ }^{\circ} 1$ (Pags. 55-72): www.utpl.edu.ec/ried/images/pdfs/volumen14-1/apuntespara.pdf 
VALERIO UREÑA, Gabriel y VALENZUELA GONZÁLEZ, Jaime Ricardo (2011): “Competencias informáticas para el e-learning 2.0", en RIED: Revista Iberoamericana de Educación a Distancia, vol.14, $\mathrm{n}^{\circ}$ 1, pp. 137-160: www.utpl.edu.ec/ried/images/pdfs/volumen14-1/competenciasinformaticas.pdf.

ZAGAL, José y BRUCKMAN, Amy (2010): “Designing Online Environments for Expert/Novice Collaboration: Wikis to Support Legitimate Peripheral Participation", en Convergence: The internacional Journal of Research into New Media Technologies, vol. 16, $\mathrm{n}^{\mathrm{o}}$ 4, pp. 451-470): http://con.sagepub.com/content/16/4/451.full.pdf + html

\section{NOTA:}

Este trabajo se enmarca dentro de los proyectos de I+D: "La producción periodística de la información política: fuentes, agendas y enfoques" (P1-1B2010-53) financiado por la Fundación Bancaja y la Universitat Jaume I (Plan de Promoción de la Investigación 2011-2013) y "Periodismo y fuentes de información política en España: relaciones y dinámicas comunicativas" (CSO2010-16313) financiado por el Ministerio de Ciencia e Innovación (Plan Nacional I+D+i 2008-2011), ambos dirigidos como investigador principal por Andreu Casero Ripollés (UJI).

\section{Cesáreo FERNÁNDEZ FERNÁNDEZ}

cesar.fernandez@uji.es

Universitat Jaume I

Fac. CC. Humanas y Sociales - Dpto. CC. Comunicación

Avda. Vicent Sos Baynat s/n - 12071 Castelló de la Plana

Profesor contratado doctor del Dpto. de CC. de la comunicación

Doctor por la Universitat Jaume I de Castellón. Es Profesor Contratado Doctor en el Dpto. de CC. De la Comunicación de la Universitat Jaume I de Castellón. Ha sido profesor en el Dpto. de Teoría de los Lenguajes de la Universitat de València. Es profesor invitado en la Licence en Communication Européenne de la Faculté Libre de Droit et Sciences Sociales del ICT de Toulouse (Francia). Forma parte del grupo de investigación ITACA (Investigación en Tecnologías Aplicadas a la Comunicación Audiovisual) y del grupo de investigación Periodismo, Comunicación y Poder, ambos de la UJI, así como del Grupo de Investigación Internacional GIRTEC (Groupe International de Recherche Text, Éducation, Communication) del ICT de Toulouse. Es investigador de comunicación en el Grupo de Investigación DATS del INTRAS (Instituto Universitario de Tráfico y Seguridad Vial) de la UV. Ha sido periodista-redactor y guionista del Departamento de Informativos de RTVV y operador de equipos en el control de continuidad del Departamento de Emisiones de RTVV. Ha sido cofundador y coordinador de Ciber@RT (Muestra Internacional de Nuevas Tecnologías en Arte y Comunicación Valencia). Publicaciones e impartición de cursos, ponencias y conferencias sobre comunicación, especialmente en torno a las nuevas tecnologías. Ha realizado diversos cortometrajes, documentales y videoartes. Ha sido miembro de varios jurados de festivales internacionales de cine, vídeo, infografía y animación. 